\title{
A cystic fibrosis patient homozygous for the new frameshift mutation 936delTA: description and clinical data
}

\author{
Miguel Chillón, Teresa Casals, Javier Giménez, Virginia Nunes, Xavier Estivill
}

\begin{abstract}
We report the identification of a new frameshift mutation (936delTA) in exon $6 \mathbf{b}$ of the CFTR gene. In the screening of 486 unrelated Spanish CF patients we found a patient homozygous for 936delTA (with consanguineous parents) and a patient heterozygous for $\Delta F 508$ and 936delTA. Genotype-phenotype correlation studies showed that 936delTA is associated with pancreatic insufficiency and chronic pulmonary colonisation.
\end{abstract}

(f Med Genet 1994;31:369-370)

Cystic fibrosis (CF) is the most common severe autosomal recessive disease in the white population, affecting about 1 in 2500 persons. ${ }^{1}$ The CF transmembrane regulator (CFTR) gene is specifically expressed in secretory epithelial cells, from pancreas, colon, sweat ducts, lung epithelium, and genital ducts. ${ }^{2}$ Mutations in the CFTR gene alter chloride secretion across the apical membrane of epithelial cells, resulting in aberrant secretions in the lungs and pancreas, and leading to chronic obstructive lung disease and digestive disorders. ${ }^{1}$

The majority of the CF mutations identified up to now (more than 350, Cystic Fibrosis Genetic Analysis Consortium data, September 1993) are associated with severe clinical presentation. Owing to the fact that the majority of CF mutations are uncommon, it is difficult to obtain reasonable genotype-phenotype correlations. Homozygosity for a given mutation provides an accurate correlation, as well as giving an indication of the severity of the mutation. However, patients homozygous for an uncommon mutation are rare. ${ }^{3}$ We report a new frameshift mutation (936delTA) in exon $6 \mathrm{~b}$ of the CFTR gene and provide clinical data of a patient homozygous for 936delTA and a patient heterozygous for $\Delta \mathrm{F} 508$ and 936delTA.

Molecular Genetics Research Institute Hospital Duran i Reynals, Autovía de Castelldefels Km 2.7, L'Hospitalet de Llobregat, 08907 Barcelona, Spain M Chillón T Casals

J Giménez

V Nunes

$\mathrm{X}$ Estivill

Correspondence to Dr Estivill.

Received 19 October 1993. Accepted for publication 30 November 1993.
Spanish CF patients, SSCP analysis was performed on a large series of CF samples. ${ }^{4}$ PCR conditions were: denaturation at $95^{\circ} \mathrm{C}$ for 30 seconds, annealing at $56^{\circ} \mathrm{C}$ for 30 seconds and extension at $74^{\circ} \mathrm{C}$ for 30 seconds for 35 cycles. The reaction mix contained $0 \cdot 1 \mu \mathrm{l}$ of $[\alpha-$ $\left.{ }^{32} \mathrm{P}\right] \mathrm{dCTP}$ (3000 Ci/mmol), $1 \mu \mathrm{l}$ of PCR buffer (Perkin Elmer Cetus N808-0006), $60 \mu \mathrm{mol} / 1$ of each dNTP, 10 pmol of each primer, $100 \mathrm{ng}$ of DNA, and 1 unit of Taq DNA polymerase, in a final volume of $10 \mu \mathrm{l}$. The primers used were 16bD1 (5' AATAATGCCCATCTGTTGAATAA $3^{\prime}$ ) and $6 \mathrm{bi}-3 .^{5}$

After PCR, DNA products of exon $6 \mathrm{~b}$ were digested with $A l u \mathrm{I}$. SSCP electophoresis was run at $4^{\circ} \mathrm{C}$ on a $6 \%$ non-denaturing polyacrylamide gel without glycerol, at $30 \mathrm{~W}$ for five hours. One abnormal band was detected in the samples analysed. DNA from the sample with the abnormal band was PCR amplified and then purified on a Strategene PrimeErase Quik column (400705). Direct automatic sequencing was performed with $3.5 \mathrm{pmol}$ of sequencing primer using a Taq DyeDeoxy ${ }^{\mathrm{TM}}$ Terminator Cycle Sequencing Kit (ABI) (401113), according to the manufacturer's recommendations. Sequencing conditions were denaturation at $96^{\circ} \mathrm{C}$ for 30 seconds, annealing at $50^{\circ} \mathrm{C}$ for 30 seconds, and extension at $60^{\circ} \mathrm{C}$ for four minutes, for 28 cycles.

\section{Results and discussion}

In the analysis of exon $6 \mathrm{~b}$ we detected one sample (89-468) with an abnormal SSCP migration pattern (figure $A$ ). Direct sequencing of the sample, using primers $16 \mathrm{bD} 1$ and 6bi-3, showed a two base pair deletion at nucleotide 936 (mutation 936delTA) (figure B). This causes a shift in the reading frame with a stop codon at the new codon 272 which should lead to truncation of the CFTR protein.

The 936delTA mutation was found associated with haplotype 22-22-17 for IVS8CAIVS17BTA-IVS17BCA ${ }^{6}$ and the deletion can easily be detected by gel electrophoresis on an $8 \%$ polyacrylamide gel. A total of three 936delTA alleles were found in the screening \begin{abstract}
of 972 CF Spanish chromosomes (3/972; final estimated frequency of $0.3 \%$ ), two in the homozygous CF patient (with consanguineous parents) and the other allele in a CF patient heterozygous for $\Delta F 508$ and 936 delTA. The grandparents of both CF patients originate from Badajoz (a province in the west of Spain), suggesting that these 936delTA alleles could have a common origin.

Materials and methods

A total of 486 unrelated Spanish families, with diagnosis of $\mathrm{CF}$, was investigated. All patien had a minimum of two positive chloride sweat tests $(\mathrm{Cl}>80 \mathrm{mmol} / \mathrm{l})$. Genomic DNA was isolated from peripheral blood lymphocytes according to standard protocols.

To identify mutations responsible for $\mathrm{CF}$ in
\end{abstract}


A

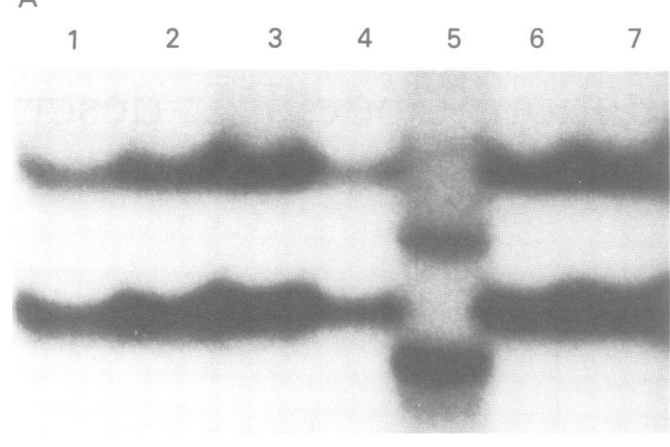

B
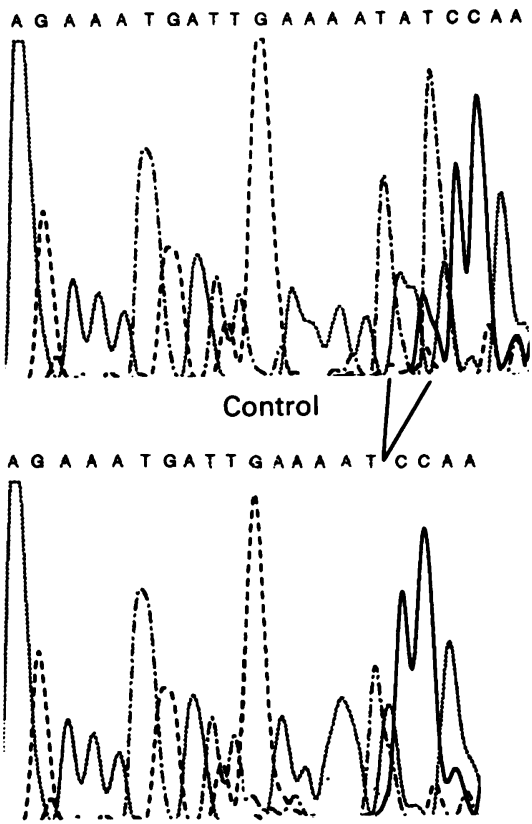

Patient 89-468

(A) SSCP analysis of exon $6 b$. Primers used were $16 b D 1$ and $6 b i-3$. SSCP-PCR products were digested with AluI. Samples were electrophoresed in non-denaturing conditions, without glycerol, at $30 \mathrm{~W}$ and at $4^{\circ} \mathrm{C}$ for five hours. Sample 5 (patient 89-468) shows an abnormal migration band pattern.

(B) Automatic sequencing of exon $6 b$ of the CFTR gene using the primer 6bi-3. CF patient sequence shows a deletion of two base pairs, at nucleotides 935 and 937 when compared to the normal sequence.

Clinical data (table) were available for both CF patients bearing mutation 936delTA. The homozygous patient (89-468) is 7 years old and was diagnosed when he was 1 month old; he is pancreatic insufficient and has chronic lung colonisation by Pseudomonas aeruginosa (since he was 2 months old), Haemophylus influenzae, and Staphylococcus aureus. He is significantly below the average weight ( 3 rd to 10 th centile) and height (10th to 25th centile) for his age. Owing to his young age $\mathrm{FEV}_{1}$ and FVC studies were not performed. Two brothers of this patient (89-468) died when they were children of unknown causes; his parents are first cousins. The heterozygous patient (91-113) is 11 years old and was diagnosed when she was 19 months old; she is pancreatic insufficient
Clinical and laboratory features of persons with 936del $T A$

\begin{tabular}{lll}
\hline & Patients & \\
\cline { 2 - 3 } & $89-468$ & $91-113$ \\
\hline Genotype & 936delTA & $936 \mathrm{delTA}$ \\
Present age & $936 \mathrm{delTA}$ & $\Delta \mathrm{F} 508$ \\
Age at diagnosis & $7 \mathrm{y}$ & $11 \mathrm{y}$ \\
Sex & $1 \mathrm{mth}$ & $1 \mathrm{y} 7 \mathrm{mth}$ \\
Sweat chloride (mEq/l) & $\mathrm{M}$ & $\mathrm{F}$ \\
Meconium ileus & No & 110 \\
Dehydration & No & No \\
Height (cm) (centile) & $115(10-25)$ & - \\
Weight (kg) (centile) & $18(3-10)$ & $21(3)$ \\
Chrispin-Norman* & 2 & 12 \\
Lung colonisation with & Yes & Yes \\
bacterial pathogens & & \\
Pancreatic insufficiency & Yes & Yes \\
Shwachman-Kulczycki $\dagger$ & 75 & 76 \\
FEV $(\%)$ predicted & - & 60 \\
FVC(\%) predicted & - & 60 \\
Other clinical features & No & No
\end{tabular}

* Chest radiograph score of Chrispin-Norman, 0 being the bes score and 36 the worst.

† Clinical score system of Shwachman-Kulczycki, of which 100 is the best clinical score. ${ }^{8}$ Forced expiratory volume in 1 second $\left(\mathrm{FEV}_{1}\right) \%$ predicted; forced vital capacity (FVC) $\%$ predicted.

and has had lung colonisations by Pseudomonas aeruginosa since she was 5 years old. She is also below the average weight ( 3 rd centile) and height (3rd centile). The CF mutation on the other chromosome is $\Delta \mathrm{F} 508$.

The 936delTA homozygote and the $936 \mathrm{delTA} / \Delta \mathrm{F} 508$ patients have allowed us to assess the clinical features of this mutation, establishing a good genotype-phenotype correlation. The clinical presentation of patients bearing 936delTA suggests its association with pancreatic insufficiency and chronic lung colonisation. This $\mathrm{CF}$ phenotype would be the result of the shift in the reading frame, which would create an early stop codon, which would produce a truncated and non-functional CFTR protein.

We thank $H$ Kruyer and $M$ Lench for help with the manu script, and Dr G Antiñolo for contributing clinical data. This work was supp de la Seguridad Social (93/0202) and the Institut Català de la Salut. MC received a fellowship from the Ministerio Españo de Educación y Ciencia.

1 Boat TF, Welsh MJ, Beaudet AL. Cystic fibrosis. In Scrive CR, Beaudet AL, Sly WS, Valle D, eds. The metabolic basis CR, Beaudet AL, Sly WS, Valle D, eds. The metabolic basis 860 .

2 Trezise AEO, Buchwald M, In vivo cell-specific expression of the cystic fibrosis transmembrane regulator. Nature of the cystic fibro

3 Nunes V, Chillón M, Dörk T, Tümmler B, Casals T, Estivill $X$. A new missense mutation (E92K) in the first transmembrane domain of the CFTR gene causes a benign cystic fibrosis phenotype. Hum Molec Genet 1993;2:79-80.

4 Chillón M, Casals T, Giménez J, Nunes V, Estivill X. Analysis of the CFTR gene in the Spanish population SSCP-screening for 60 known mutations and identification of four new mutations (Q30X, A120T, 1812-1G $\rightarrow C$ and 3667del4). Hum Mutat (in press)

5 Zielensky J, Rozmahel R, Bozon D, et al. Genomic DNA sequence of the cystic fibrosis transmembrane regulato (CFTR) gene. Genomics 1991;10:214-28

6 Morral N, Nunes V, Casals T, et al. Microsatellite haplotypes for cystic fibrosis: mutation frameworks and evolutionary tracers. Hum Molec Genet 1993;2:1015-22.

7 Chrispin AR, Norman AP. The systematic evaluation of the chest radiograph in cystic fibrosis. Pediatr Radiol 1974;2:101-10.

8 Shwachman H, Kulczycki L. Long-term study of 105 patients with cystic fibrosis. Am $\mathcal{F}$ Dis Child 1958;96:6-15. 